\title{
Structural, Magnetic and Electrical Properties of Co-
}

\section{Doped Barium Monoferrite $\mathrm{BaFe}_{2} \mathrm{O}_{4}$}

\author{
Samar I. Abdelsalam ${ }^{\mathrm{a}}$, Adel Maher Wahba ${ }^{\mathrm{a},}$,, M.A. Amer ${ }^{\mathrm{b}}$, A.S. Doma ${ }^{\mathrm{c}}$, Bahaa Eddin M. Moharram ${ }^{\mathrm{a}}$ \\ ${ }^{a}$ Faculty of Engineering, Department of Engineering Physics and Mathematics, Tanta University, Egypt \\ ${ }^{b}$ Department of Physics, Faculty of Science, Tanta University, Egypt \\ ${ }^{c}$ Polymeric Materials Research Dep., Advanced Technology and New Materials Research Institute (ATNMRI), City of \\ Scientific Research and Technological Applications (SRTA-City), New Borg El-Arab City 21934, Alexandria, Egypt \\ *Corresponding author: adel.mousa@f-eng.tanta.edu.eg
}

\begin{abstract}
Cobalt-substituted barium monoferrite with the formula $\mathrm{BaCo}_{x} \mathrm{Fe}_{2-x} \mathrm{O}_{4}(x=0.0-0.4$, step 0.1$)$ has been prepared through the sol-gel autocombustion method. Phase purity for prepared samples sintered at 700 and $1050^{\circ} \mathrm{C}$ was analyzed by $\mathrm{X}$-ray diffraction (XRD) patterns that indicated the formation of the typical orthorhombic phase for the samples. Fouriertransform infrared (FTIR) spectroscopy was used to investigate the effect of cobalt doping on the vibrational modes of the studied samples. Scherrer and Williamson-Hall formulae were used to define the microstrian and the crystallite size being in the range of 44.1 to $59.7 \mathrm{~nm}$, which was further confirmed with transmission electron microscopy (TEM) images. Magnetic characteristics including magnetic saturation and coercivity were obtained from hysteresis loops traced using vibrating sample magnetometry (VSM). Magnetic properties were correlated with the composition of the prepared samples. Finally, dielectric measurements were operated to further confirm the structural and magnetic analysis.
\end{abstract}

\section{INTRODUCTION}

Along the past few decades, magnetic nanomaterials have been under intense investigation due to their versatile use in technological application including drug delivery [1], magneto-optic media [2], radar absorption [3] and modern microwave devices [4]. This is attributed to the distinctive properties exhibited by them such as excellent chemical stability, good dielectric properties, and the flexibility of tailoring its magnetic properties [5-7].

Spinel ferrites are assigned by the formula $\mathrm{MFe}_{2} \mathrm{O}_{4}$, where $\mathrm{M}$ refers to a divalent metal cation $(\mathrm{M}=\mathrm{Ba}, \mathrm{Sr}, \mathrm{Ni}, \mathrm{Co}$, etc. $)$. The structure of these materials depends mainly on the cation $\mathrm{M}$ and/or its substituent. For example $\mathrm{CoFe}_{2} \mathrm{O}_{4}$ has cubic structure [8], that of $\mathrm{SrFe}_{2} \mathrm{O}_{4}$ is hexagonal [9] and that of $\mathrm{BaFe}_{2} \mathrm{O}_{4}$ is orthorhombic [10]. Generally, less symmetric structures are produced when the difference between the ionic radius of the cation $\mathrm{M}$ and that of $\mathrm{Fe}^{3+}$ cation is larger. For each of these structures $\mathrm{M}$ and Fe cations occupy two characterizing sites, namely octahedral and tetrahedral sites specified by the lattice made up by oxygen anions. Among the spinel ferrites, barium monoferrite (to distinguish it from hexagonal barium ferrite $\mathrm{BaFe}_{12} \mathrm{O}_{19}$ ) is characterized by the unique combination of moderate magnetization and large coercivity, which permits its use in quite specified applications, e.g. magnetic storage and permanent magnets [11]. Moreover, many works have reported its wide use as photocatalytic [12, 13] and pigments [14].
The magnetic properties of $\mathrm{BaFe}_{2} \mathrm{O}_{4}$, like other spinel ferrites, could be controlled using the substitution technique of either $\mathrm{Ba}^{2+}$ [9] and/or $\mathrm{Fe}^{3+}$ cations. The substitution of $\mathrm{Fe}^{3+}$ could be by either trivalent ions $\left(\mathrm{Al}^{3+}, \mathrm{Cr}^{3+}\right)[15,16]$ and/or divalent ions $\left(\mathrm{Zn}^{2+}, \mathrm{Co}^{2+}\right)[17,18]$.

Several preparation methods have been reported by researchers for synthesizing ferrite materials with the desired composition stoichiometry, structure, and morphology to achieve the properties compatible with the specified application. Such methods include solid state or ceramic [19], co-precipitation [20], hydrothermal [21], and sol-gel autocombustion [22]. The latter presents some advantages among which, simple reagents, inexpensive equipment, doping control, low-temperature production, good stoichiometric control, homogenous mixing, and finally, the short preparation time [23-25].

In the present work, the substitution of $\mathrm{Co}^{2+}$ in $\mathrm{BaCo}_{x} \mathrm{Fe}_{2-}$ ${ }_{x} \mathrm{O}_{4}$ system has been investigated from the point of view of its effects on structure, magnetic and dielectric properties. XRD, TEM, and IR spectroscopy were used to analyze the structural properties including phase purity, crystallite size, lattice parameters and strain for prepared samples sintered at both 700 and $1050^{\circ} \mathrm{C}$. VSM was used to obtain saturation magnetization, coercivity and remanence. The effect of $\mathrm{Co}^{2+}$ doping on the magnetic properties of $\mathrm{BaFe}_{2} \mathrm{O}_{4}$ has been investigated and correlated with the structural and electrical properties.

\section{EXPERIMENTAL}

\section{A. Preparation of Nanocrystalline $\mathrm{BaCO}_{x} \mathrm{Fe}_{2}{ }_{-} \mathrm{O}_{4}$}

Nanocrystalline Co-doped barium monoferrite samples with the formula $\mathrm{BaCo}_{x} \mathrm{Fe}_{2-x} \mathrm{O}_{4}(x=0.0-0.4$, step 0.1) were synthesized using sol-gel autocombustion technique. The starting materials were analytical grade nitrates of $\mathrm{Co}\left(\mathrm{NO}_{3}\right)_{2} \cdot 6 \mathrm{H}_{2} \mathrm{O}, \quad \mathrm{Ba}\left(\mathrm{NO}_{3}\right)_{2}, \quad$ and $\mathrm{Fe}\left(\mathrm{NO}_{3}\right)_{3} .9 \mathrm{H}_{2} \mathrm{O}$ and anhydrous citric acid $\mathrm{C}_{6} \mathrm{H}_{8} \mathrm{O}_{7}$. Stoichiometric amounts of the metal nitrates were dissolved separately in minimum amounts of distilled water, and then mixed together. Citric acid solution was then added to the nitrates solution in a molar ratio of 1:1 (to chelate $\mathrm{Ba}^{2+}, \mathrm{Co}^{2+}, \mathrm{Fe}^{3+}$ ions) and then, a stirring process was operated for one hour. Meanwhile, ammonium hydroxide was added drop by drop to adjust the $\mathrm{pH}$ number from $\sim 1$ (for the acidic solution) to 7 , after which the stirring process has been allowed to continue for further an hour. Heating at $100^{\circ} \mathrm{C}$ was then initiated on the hot plate 
to enforce water evaporation till the formation of a dark vicious gel was observed. Continuing the heating process initiated the autocombustion process from the hottest point of the formed gel, which then propagates up like an erupting volcano, forming an ash-like powder. The latter was ground in an agate mortar to obtain a loose powder. For each composition, the fine powder was divided into two parts for being sintered in a programmable muffle furnace at 700 and $1050{ }^{\circ} \mathrm{C}$ for $2 \mathrm{~h}$, separately, with a heating rate of $5^{\circ} \mathrm{C} / \mathrm{min}$.

\section{B. Characterization techniques}

XRD diffraction patterns of the sintered samples with different compositions were recorded using a Philips diffractometer (X'pert MPD) with a goniometer using $\mathrm{Cu}-\mathrm{K}_{\alpha}$ radiation $(\lambda=1.54056 \AA)$. The diffracted intensities were collected in the step-scan mode (step size $2 \theta=0.03^{\circ}$ with step time $1.5 \mathrm{~s}$ ). The angular range was 15 to $70^{\circ}$. The recorded patterns were used for performing the structural analysis for the studied samples, from which information such as phase structure, lattice parameters, crystallite size, and unit-cell volume were achieved. Infrared spectroscopy (FTIR) of the prepared samples was carried out on Bruker Tensor 27 FTIR Spectrometer in the range of $200-900 \mathrm{~cm}^{-1}$ to confirm the phase structure of the prepared $\mathrm{BaFe}_{2} \mathrm{O}_{4}$ sample and to analyze the changes induced on it upon doping with $\mathrm{Co}^{2+}$. For this purpose, $0.2 \mathrm{mg}$ of the ferrite was mixed with $200 \mathrm{mg}$ of $\mathrm{KBr}$ and pressed into pellets. The powder morphology was recorded by TEM images (TEM, JEOL JEM-100CX with an accelerating voltage extending up to $100 \mathrm{kV}$ ) (HR-TEM, Tecnai G20, FEI, Netherland) with an accelerating voltage of $200 \mathrm{kV}$.. Magnetic characteristics of the studied samples, namely saturation magnetization, remanence, and the coercive field were deduced from $M-H$ hysteresis loops traced at room temperature, using VSM (Lake Shore-7400) with an applied field extending up to 20KOe). The electrical properties including the ac conductivity and the dielectric constant (with its real, $\varepsilon^{\prime}$, and imaginary, $\varepsilon^{\prime \prime}$, parts) were achieved at room temperature using a IN 3536 LCR Meter in the frequency range of $1 \mathrm{MHz}$ to $8 \mathrm{MHz}$. The ac conductivity $\left(\sigma_{\mathrm{ac}}\right)$ was obtained using the relation $\sigma_{\mathrm{ac}}=$ $2 \pi f \varepsilon_{0} \varepsilon^{\prime} \tan \delta$, where $f$ is the frequency $(\mathrm{Hz}), \varepsilon_{0}$ is the electrical permittivity of free space, $\varepsilon^{\prime}$ is the dielectric constant and $\tan \delta=\varepsilon^{\prime} / \varepsilon^{\prime \prime}$ is dielectric loss factor. The parameter $\varepsilon^{\prime}$ was determined from the formula $C d / \varepsilon_{\mathrm{o}} A$ where $C$ is the capacitance, $d$ is the pellet thickness and $A$ is its cross-sectional area. The imaginary part of the dielectric constant is depicted from the formula $\varepsilon^{\prime \prime}=d G / 2 \pi f \varepsilon_{0} A$, where $\mathrm{G}$ is the measured conductance $(1 / R)$.

\section{RESULTS AND DISCUSSION}

\section{A. Structural analysis}

The XRD patterns for the prepared $\mathrm{BaCo}_{x} \mathrm{Fe}_{2-x} \mathrm{O}_{4}(x=0.0$ to 0.4 , step 0.1) sintered at $700{ }^{\circ} \mathrm{C}$ are shown in Fig. 1(a). The XRD pattern quite matches that of the orthorhombic crystal structure of barium monoferrite (identified by JCPDS card 70-2468). The peak at $2 \theta=31.09^{\circ}$ (indicated with $\bullet$ ), recorded for samples with $x \geq 0.2$, corresponds to the maximum-intensity peak, of the diffraction plane (110), for the cubic pervoskite phase of $\mathrm{BaFeO}_{3}$ (JCPDS card 75-0426). That pervoskite-phase impurity increases with Co doping as indicated from the figure. Fig. 1(b) shows the diffraction
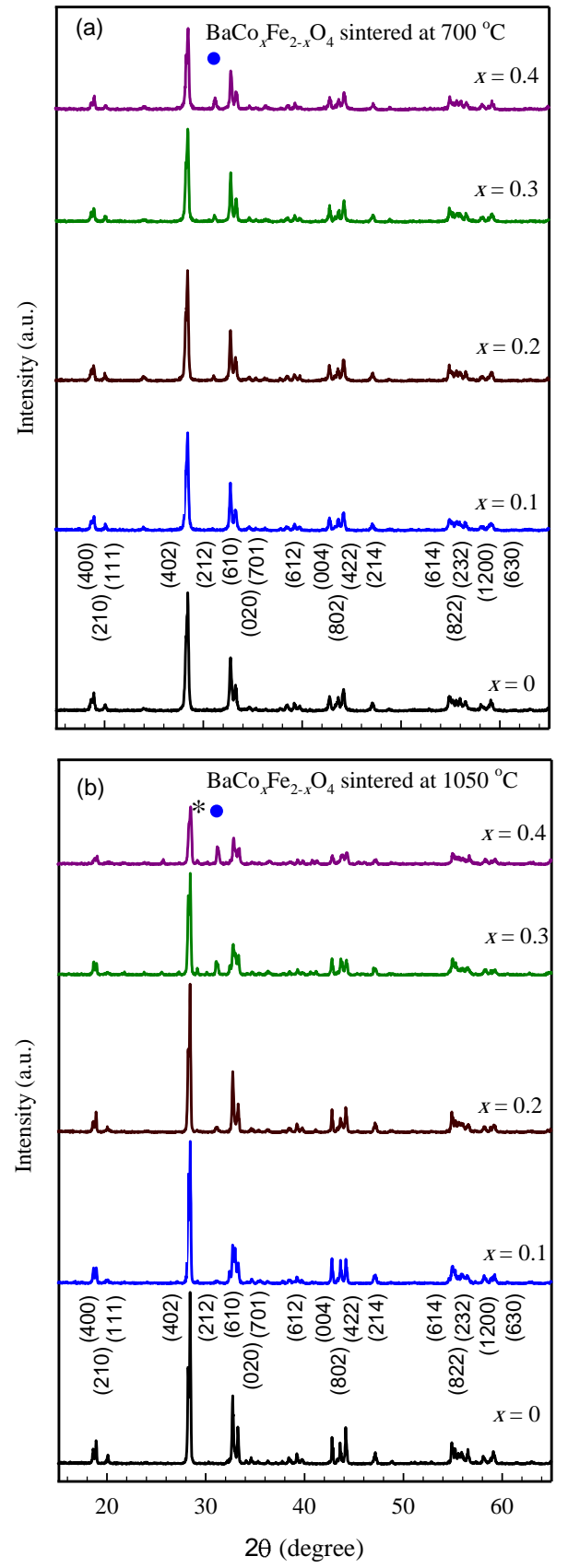

Figure 1. XRD pattern of $\mathrm{BaCo}_{x} \mathrm{Fe}_{2-x} \mathrm{O}_{4}$ samples sintered at (a) $700{ }^{\circ} \mathrm{C}$ and (b) $1050{ }^{\circ} \mathrm{C}$. $\bullet$ indicates $\mathrm{BaFeO}_{3}$ and * indicates $\mathrm{Ba}_{2} \mathrm{FeO}_{4}$.

patterns of the same samples sintered at $1050{ }^{\circ} \mathrm{C}$. Extra feeble peak appeared at $2 \theta=29.2^{\circ}$ (indicated with $*$ ) corresponding to the orthorhombic $\mathrm{Ba}_{2} \mathrm{FeO}_{4}$ oxide, with maximum-intensity diffraction plan (112) (JCPDS card 231022). Worth to mention is that sintering at $1050{ }^{\circ} \mathrm{C}$ enhanced the sharpness and intensity of the diffraction peaks for $x \leq 0.2$, indicating the enrichment of size and crystallinity. It is expected that $\mathrm{BaFeO}_{3}$ and $\mathrm{Ba}_{2} \mathrm{FeO}_{4}$ impurities (for $x=$ 0.3 and 0.4 samples) impeded the crystal growth of the original orthorhombic structure of $\mathrm{BaCo}_{x} \mathrm{Fe}_{2-x} \mathrm{O}_{4}$.

The crystallite size was estimated by two well-known methods. The first used the broadening of the peaks according to Scherrer's formula [26], $D=\mathrm{k} \lambda /(\beta \cos \theta)$, Where $D$ is the particle size, is $\mathrm{X}$-ray wavelength, $\mathrm{k}$ is a 
shape-factor constant taken as $0.94, \beta$ is the peak full-width at half-maximum (FWHM) intensity and $2 \theta$ is the diffraction angle. The second method involved the use of WilliamsonHall strain-size formula [27]:

$$
(d \beta \cos \theta)^{2}=\frac{\mathrm{k}}{D} d^{2} \beta \cos \theta+\left(\frac{\varepsilon}{2}\right)^{2}
$$

Where $d$ is the spacing between diffraction plans corresponding to $(h, k, l)$ lattice indices and $\varepsilon$ is the strain. The the particle size is determined from the slope of the linearly fitted data of $(\mathrm{d} \beta \cos \theta)^{2}$ on the $\mathrm{y}$ axis versus $\left(d^{2} \beta \cos \theta\right)$ on the $x$ axis. The root of the $y$-intercept gives the strain. An example of the use of both methods is shown in Fig. $2 a, b$, for the sample with $x=0.2$ sintered at $700^{\circ} \mathrm{C}$. The crystallite size and microstrian for all samples and for both sintering temperatures are illustrated in Table 1 . It is clear that for sintering temperature of $700{ }^{\circ} \mathrm{C}$, the crystallite size hardly changed with $\mathrm{Co}^{2+}$ doping $(40-44.2 \mathrm{~nm})$, while for sintering at $1050{ }^{\circ} \mathrm{C}$, the crystallite size and crystallinity (see Fig. 1b) decreased with dopant content, being attributed to phase impurities. This is confirmed when considering the significant growth of the undoped $\mathrm{BaFe}_{2} \mathrm{O}_{4}$ sample (from 40.9 to $57.9 \mathrm{~nm}$ ) upon increasing the sintering temperature to $1050{ }^{\circ} \mathrm{C}$.

The orthorhombic-phase lattice parameters of the studied samples ( $a, b$ and $c$ ) were calculated using (suggested) Miller indices $(h, k$, and $l$ ) corresponding to the XRD reflections and their $d$ spacing according to lattice geometry equation [28]:

$$
\frac{1}{d^{2}}=\frac{h^{2}}{a^{2}}+\frac{k^{2}}{b^{2}}+\frac{l^{2}}{c^{2}}
$$

Using successive iterations, the deduced lattice parameters were used to attain theoretical values for the $d$-spacing of the diffraction planes. The maximum standard deviation of experimental and theoretical $d$-spacing values was less than 0.001 . The unit cell volume was calculated using $V=a b c$. The lattice parameters and unit cell volume for all samples are listed in Table 2. Variation of the unit cell volume with Co concentration for both sintering temperatures is illustrated in Fig.3. There is a slightly decrease in unit cell
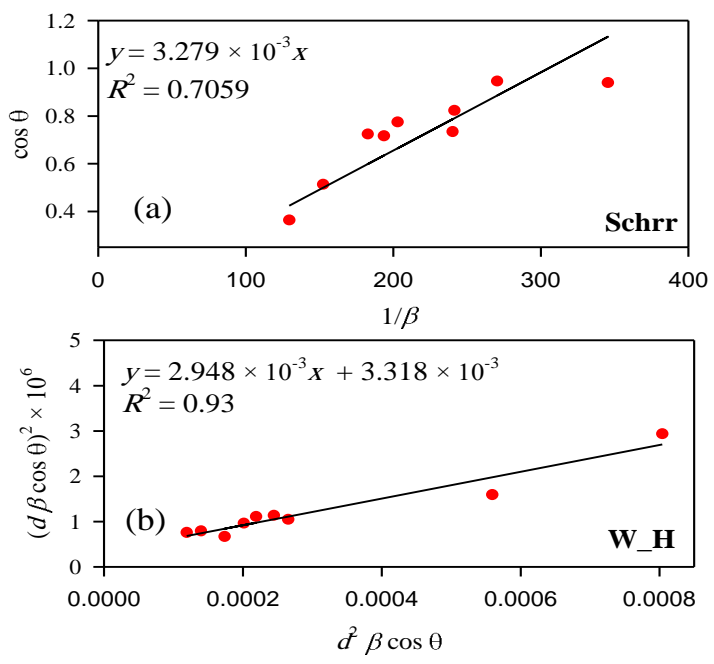

Figure 2. (a) Scherrer plot and (b) W-H strain-size plot of $\mathrm{BaCo}_{0.2} \mathrm{Fe}_{1.8} \mathrm{O}_{4}$ sintered at $700{ }^{\circ} \mathrm{C}$.
CRYSTALLITE SIZE $(D)$ AND STRAIN $(\varepsilon)$ OF $\mathrm{BaCo}_{x} \mathrm{Fe}_{2-x} \mathrm{O}_{4}$ SINTERED AT 700 AND

\begin{tabular}{|c|c|c|c|c|c|c|}
\hline \multirow{3}{*}{$x$} & \multicolumn{4}{|c|}{$D(\mathrm{~nm})$} & \multicolumn{2}{|c|}{$\varepsilon \times 10^{-3}$} \\
\hline & \multicolumn{2}{|c|}{ Scherrer } & \multicolumn{2}{|c|}{ W-H } & \multirow{2}{*}{$700{ }^{\circ} \mathrm{C}$} & \multirow{2}{*}{$1050^{\circ} \mathrm{C}$} \\
\hline & $700^{\circ} \mathrm{C}$ & $1050^{\circ} \mathrm{C}$ & $700{ }^{\circ} \mathrm{C}$ & $1050^{\circ} \mathrm{C}$ & & \\
\hline 0.0 & 40.9 & 57.9 & 35.0 & 57.5 & 0.974 & 0.789 \\
\hline 0.1 & 40.0 & 56.6 & 30.3 & 42.1 & 0.798 & 0.546 \\
\hline 0.2 & 42.3 & 53.3 & 39.2 & 38.3 & 1.152 & 0.721 \\
\hline 0.3 & 44.2 & 43.7 & 38.3 & 45.5 & 0.721 & 1.188 \\
\hline 0.4 & 43.4 & 44.1 & 32.4 & 35.8 & 0.782 & 0.842 \\
\hline
\end{tabular}
$1050{ }^{\circ} \mathrm{C}$

TABLE 2

LATTICE PARAMETERS AND UNIT CELL VOLUME OF $\mathrm{BaCo}_{x} \mathrm{Fe}_{2-x} \mathrm{O}_{4}$ samples SINTERED AT 700 AND $1050{ }^{\circ} \mathrm{C}$

\begin{tabular}{|l|cccccc|cc|}
\hline \multicolumn{3}{|l}{ Lattice Parameters $(\AA)$} & & \multicolumn{2}{l|}{$\begin{array}{l}\text { Unit-cell vol. } \\
\left(\AA^{3}\right)\end{array}$} \\
\hline \multirow{2}{*}{$x$} & $700{ }^{\circ} \mathrm{C}$ & & & \multicolumn{2}{c}{$1050{ }^{\circ} \mathrm{C}$} & & $700{ }^{\circ} \mathrm{C}$ & $\begin{array}{c}1050 \\
{ }^{\circ} \mathrm{C}\end{array}$ \\
\cline { 2 - 11 } & $a$ & $b$ & $c$ & $a$ & $b$ & $c$ & $V$ & $V$ \\
\hline 0.0 & 19.027 & 5.385 & 8.451 & 19.05 & 5.382 & 8.448 & 865.9 & 866.0 \\
0.1 & 19.030 & 5.385 & 8.461 & 19.02 & 5.376 & 8.452 & 867.1 & 864.3 \\
0.2 & 19.025 & 5.384 & 8.463 & 19.03 & 5.381 & 8.446 & 867.0 & 864.9 \\
0.3 & 19.025 & 5.376 & 8.440 & 19.02 & 5.379 & 8.447 & 863.2 & 864.0 \\
0.4 & 19.010 & 5.376 & 8.441 & 18.97 & 5.367 & 8.455 & 862.7 & 860.6 \\
\hline
\end{tabular}

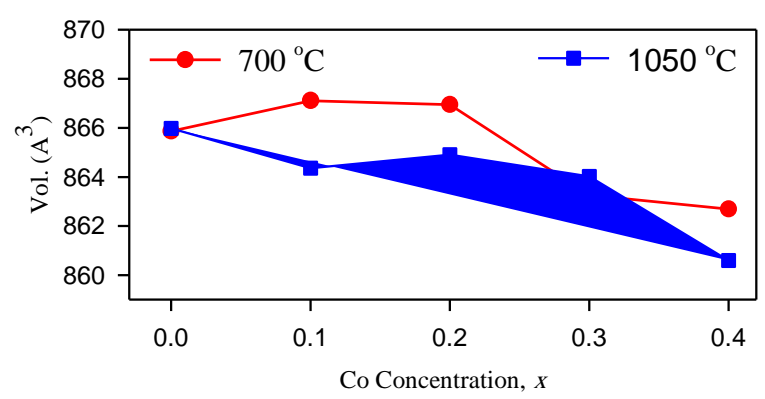

Figure 3.unit cell volume for $\mathrm{BaCo}_{x} \mathrm{Fe}_{2-x} \mathrm{O}_{4}$ sintered at 700 and $1050{ }^{\circ} \mathrm{C}$

volume with increasing the dopant content for $x \geq 0.2$. The monotonic decrease in volume cannot be explained on the basis of the difference between the ionic radii of $\mathrm{Co}^{2+}$ ion $(0.74 \AA)$ and $\mathrm{Fe}^{3+}$ ion $(0.64 \AA)$. As such difference is expected to induce lattice expansion as recorded for sample with $x=0.1$ sintered at $700{ }^{\circ} \mathrm{C}$. This behavior might be interpreted as follow. For sample with $x=0.1$ sintered at 700 ${ }^{\circ} \mathrm{C}, \mathrm{Co}^{2+}$ cation simply substitutes $\mathrm{Fe}^{3+}$ causing both the creation of electronic charge imbalance and an increase in the unit cell volume as compared with the undoped $\mathrm{BaFe}_{2} \mathrm{O}_{4}$ sample (due to the larger ionic radius of $\mathrm{Co}^{2+}$ ). However, upon sintering to $1050{ }^{\circ} \mathrm{C}$, enough energy is supplied for the oxidation of $\mathrm{Co}^{2+}$ to $\mathrm{Co}^{3+}(0.545 \AA)$ to achieve the charge balance with a resulting reduction in the unit cell volume. Magnetic behavior of this sample supports this scenario, as will be discussed below. For higher concentration of $\mathrm{Co}^{2+}(x$ $\geq 0.2$ ) and for either sintering temperatures, the induced non stoichiometry is compensated by the occurrence of higher valence state of $\mathrm{Fe}^{3+}$ cations, i.e. $\mathrm{Fe}^{4+}$ with the smaller ionic radius $(0.585 \AA)$ resulting in the reduction of the unit cell volume. This could be confirmed by the appearance of traces of $\mathrm{BaFeO}_{3}$ and/or $\mathrm{Ba}_{2} \mathrm{FeO}_{4}$ impurities in XRD patterns; either of those compounds has $\mathrm{Fe}^{4+}$ cations. The effect of 

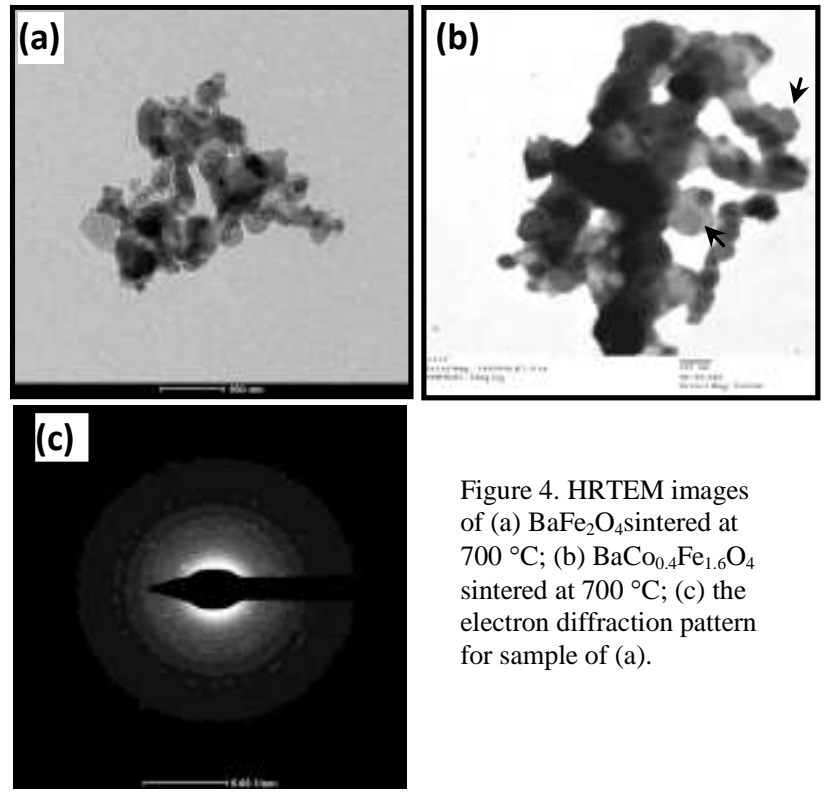

Figure 4. HRTEM images of (a) $\mathrm{BaFe}_{2} \mathrm{O}_{4}$ sintered at $700{ }^{\circ} \mathrm{C}$; (b) $\mathrm{BaCo}_{0.4} \mathrm{Fe}_{1.6} \mathrm{O}_{4}$ sintered at $700{ }^{\circ} \mathrm{C}$; (c) the electron diffraction pattern for sample of (a).

replacing $\mathrm{Fe}^{3+}$ cation by $\mathrm{Co}^{2+}$ could be simply clarified by the following chemical equation $2 \mathrm{Fe}^{3+} \rightarrow \mathrm{Co}^{2+}+\mathrm{Fe}^{4+}$.

To attain a better view of the crystallite size and morphology HRTEM images of $\mathrm{BaFe}_{2} \mathrm{O}_{4}$ and $\mathrm{BaCo}_{0.4} \mathrm{Fe}_{1.6} \mathrm{O}_{4}$ sintered at $700{ }^{\circ} \mathrm{C}$ was shown at Fig $(4 a$ and $b)$. The powder morphology was recorded by TEM images (TEM, JEOL JEM-100CX with an accelerating voltage extending up to $100 \mathrm{kV}$ ). Fig. $4 c$ shows the diffraction pattern of $\mathrm{BaFe}_{2} \mathrm{O}_{4}$ sintered at $700{ }^{\circ} \mathrm{C}$. The particles have a tendency to agglomerate probably due to the magnetic interaction between the particles [29]. The average particle size obtained from TEM images agrees quite well with that deduced from the XRD data analysis. The arrows in Fig. $4 b$ clarify the formation of perfectly-packed orthorhombic crystallites. The crystallinity of undoped barium ferrite is a bit incomplete as compared to that of $\mathrm{BaCo}_{0.4} \mathrm{Fe}_{1.6} \mathrm{O}_{4}$; the particles are less crystallized with distorted shapes and electron diffraction pattern is relatively dim. Barium monoferrite is reported to

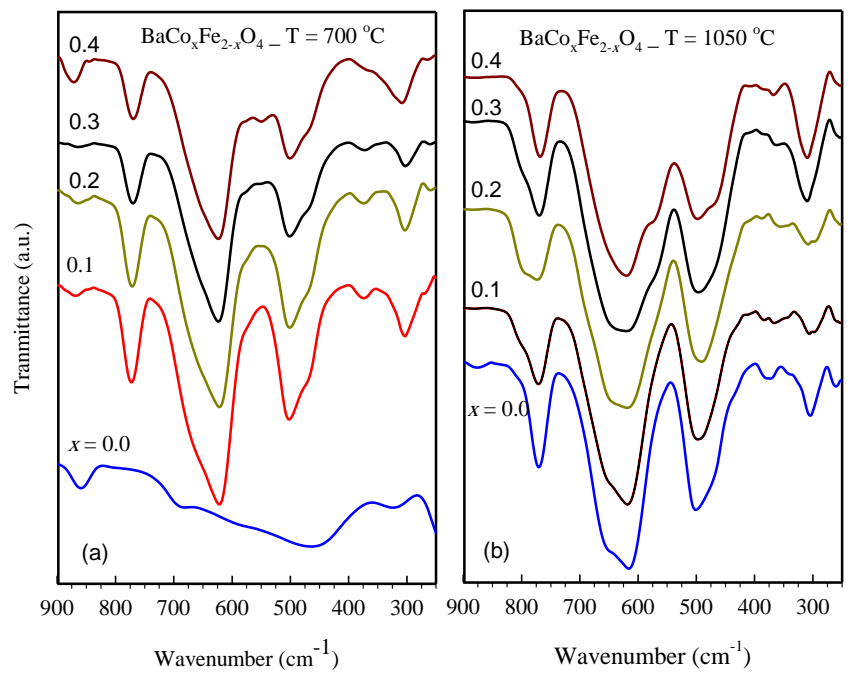

Figure 5. FTIR absorption spectra of barium cobalt ferrites with the formula $\mathrm{BaCo}_{x} \mathrm{Fe}_{2-x} \mathrm{O}_{4}$ with different substitutions sintered at (a) $700{ }^{\circ} \mathrm{C}$ and (b) fully crystallizes at $900{ }^{\circ} \mathrm{C}[9]$, which has been assured from our XRD data (see Fig. $1 a, b$ ).

Figure $(5 a, b)$ shows FTIR spectra of $\mathrm{BaCo}_{x} \mathrm{Fe}_{2-x} \mathrm{O}_{4}$ with different $\mathrm{Co}^{2+}$ ion content sintered at 700 and $1050^{\circ} \mathrm{C}$. As just explained by the above discussion, IR spectrum for undoped $\mathrm{BaFe}_{2} \mathrm{O}_{4}$ sintered at $700{ }^{\circ} \mathrm{C}$ did not show any vibrational modes (Fig $a$ ). However, spectra for the Codoped samples showed well-identified behavior. Vibrational peaks at 302, 377, 503, 630 and $775 \mathrm{~cm}^{-1}$ were recorded for each sample for both sintering temperatures. All these peaks are characteristics for the orthorhombic phase of $\mathrm{BaFe}_{2} \mathrm{O}_{4}$ $[13,30-33]$. With increasing Co content, the peak around $302 \mathrm{~cm}^{-1}$ becomes sharper which might attribute to the vibrational coupling between $\mathrm{Fe}(\mathrm{Ba})-\mathrm{O}$ and $\mathrm{Co}-\mathrm{O}$. It could be inferred that $\mathrm{Co}^{2+}$ joined well the internal orthorhombic phase and the $\mathrm{BaCo}_{x} \mathrm{Fe}_{2-x} \mathrm{O}_{4}$ was successfully prepared by autocombustion sol-gel method [34]. Worth to mention is that a vibrational shoulder was recorded at around $802 \mathrm{~cm}^{-1}$. In $\mathrm{La}_{1-x} \mathrm{Ca}_{x} \mathrm{FeO}_{3}$ pervoskite investigated by Barbero et al. [35], new band was observed at around $877 \mathrm{~cm}^{-1}$, whose intensity increased with the increase of divalent $\mathrm{Ca}$ content. They assigned this band to the formation of $\mathrm{Fe}^{4+}$. Moreover, Gholizadeh et al [36] reported that substituting Co in $\mathrm{LaFe}_{1-y} \mathrm{Co}_{y} \mathrm{O}_{3}$ resulted in the oxidation of $\mathrm{Co}^{2+}$ and $\mathrm{Fe}^{3+}$ to $\mathrm{Co}^{3+}$ and $\mathrm{Fe}^{4+}$ respectively. Based on the findings in literature and according to the results of our structural analysis, substitution trivalent $\mathrm{Fe}^{3+}$ cation by divalent $\mathrm{Co}^{2+}$ one may enforce oxidation of $\mathrm{Co}^{2+}$ to $\mathrm{Co}^{3+}$ and/or $\mathrm{Fe}^{3+}$ to $\mathrm{Fe}^{4+}$ in order to maintain the electronic charge neutrality. The probability of this oxidation process increases with either degree of substitution ( $x$ value) or by increasing the sintering temperature. Accordingly, we can assign the shoulder at $802 \mathrm{~cm}^{-1}$ to the $\mathrm{Fe}^{4+}$ ions formation.

\section{B. Magnetic properties}

Magnetic hysteresis $(M-H)$ loops for $\mathrm{BaCo}_{x} \mathrm{Fe}_{2-x} \mathrm{O}_{4}$ samples $(x=0.0-0.4$, step 0.1$)$ sintered at $700^{\circ} \mathrm{C}$ and $1050^{\circ} \mathrm{C}$ are depicted in Fig. $6(a, b)$ respectively. The magnetic characteristics including magnetization at $20 \mathrm{kOe}$ $\left(M_{20}\right)$, coercivity $\left(H_{\mathrm{c}}\right)$, and remnant field $\left(M_{\mathrm{s}}\right)$ are listed in Table 3 and Table 4 for sintering temperature 700 and 1050 ${ }^{\circ} \mathrm{C}$, respectively. The saturation magnetization $\left(M_{\mathrm{s}}\right)$ was deduced by plotting $M$ versus $1 / H$ and taking the limit as $H$ approaches $\infty[37,38]$. For the barium monoferrite sample ( $x$ $=0.0$ ) sintered at $700{ }^{\circ} \mathrm{C}$, a typical $M-H$ loop for barium
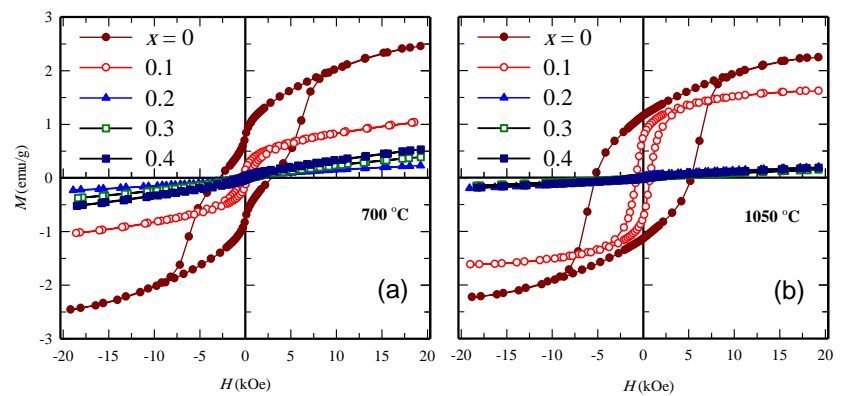

Figure 6. Hysteresis pattern of undoped and cobalt doped barium ferrites $\mathrm{BaCo}_{x} \mathrm{Fe}_{2-x} \mathrm{O}_{4}$ sintered at (a) $700{ }^{\circ} \mathrm{C}$ and (b) $1050{ }^{\circ} \mathrm{C}$ 
monoferrite is exhibited [39]. The necking appearing at relatively weak applied field could be attributed to the the incomplete crystallinity that could appear in a nonuniform particle size distribution (a mixture of small and large particle) which agrees with TEM images for this sample. Small particles could exhibit antiferromagnetic behavior which induces additional character to a well-known ferromagnetic behavior of $\mathrm{BaFe}_{2} \mathrm{O}_{4}$. This possibility is supported by the TEM image of that sample besides the absence of a clear IR spectrum for it (see Fig. 5a). In addition, previous works recorded similar observation, for $\mathrm{SrFe}_{12} \mathrm{O}_{19}$ and $\mathrm{BaFe}_{12} \mathrm{O}_{19}$, with no explanation [34, 40].

TABLE 3

MAGNETIC PROPERTIES AND PARTICLE SIZE $D$ OF $\mathrm{BaCo}_{x} \mathrm{Fe}_{2-x} \mathrm{O}_{4}$ SAMPLES SINTERED AT $700^{\circ} \mathrm{C}$

\begin{tabular}{|c|ccccc|}
\hline$x$ & $\begin{array}{c}M_{\mathrm{r}} \\
(\mathrm{e} u / \mathrm{g})\end{array}$ & $\begin{array}{c}M_{20} \\
(\mathrm{e} m u / g)\end{array}$ & $M_{\mathrm{s}}(\mathrm{emu} / \mathrm{g})$ & $H_{\mathrm{c}}$ & $\begin{array}{c}D \\
(\mathrm{~nm})\end{array}$ \\
\cline { 2 - 6 } 0.0 & 0.772 & 2.46 & 2.87 & 2880 & 40.9 \\
0.1 & 0.147 & 1.03 & 1.33 & 315 & 40.0 \\
0.2 & 0.013 & 0.231 & & 342 & 42.3 \\
0.3 & 0.024 & 0.387 & & 485 & 44.2 \\
0.4 & 0.033 & 0.532 & & 453 & 43.4 \\
\hline
\end{tabular}

MAGNETIC PROPERTIES AND PARTICLE SIZE $D$ OF $\mathrm{BaCo}_{x} \mathrm{Fe}_{2-x} \mathrm{O}_{4}$ SAMPLES SINTERED AT $1050^{\circ} \mathrm{C}$

\begin{tabular}{|c|ccccc|}
\hline $\boldsymbol{x}$ & $\begin{array}{c}M_{r} \\
(\mathrm{e} m \mathrm{~g} / \mathrm{g})\end{array}$ & $\begin{array}{c}M_{20} \\
(\mathrm{e} \mathrm{mu} / \mathrm{g})\end{array}$ & $\begin{array}{c}M_{s} \\
(e \mathrm{mu} / \mathrm{g})\end{array}$ & $H_{c}$ & $\begin{array}{c}D \\
(\mathrm{~nm})\end{array}$ \\
\hline 0.0 & 1.153 & 2.44 & 2.56 & 5260 & 57.9 \\
0.1 & 0.749 & 1.17 & 1.75 & 761.4 & 56.6 \\
0.2 & 0.0247 & 0.200 & & 436.9 & 53.3 \\
0.3 & 0.0062 & 0.153 & & 402.6 & 47.0 \\
0.4 & 0.0149 & 0.188 & & 578.5 & 44.1 \\
\hline
\end{tabular}

Sintering at $1050{ }^{\circ} \mathrm{C}$ was sufficient to enhance the crystallinity and to increase the crystallite size from 40.9 to $57.9 \mathrm{~nm}$, the fact which resulted in almost doubling the coercivity (2880 to $5260 \mathrm{Oe}$ ).

Low substitution of Co cations $(x=0.1)$ resulted in a clear reduction of magnetization and a collapse in coercivity, which could be explained as follows. First, the magnetic moment of $\mathrm{Co}^{2+}(3 \mu \mathrm{B})$ cation is smaller than that of the substituted $\mathrm{Fe}^{3+}(5 \mu \mathrm{B})$ one. Second, the substitution itself weakens the strength of the magnetic exchange interaction of $\mathrm{Fe}^{3+}-\mathrm{O}^{2-}-\mathrm{Fe}^{3+}$ [41]. Finally, the reduction in $M_{\mathrm{S}}$ could be related to the existence of some oxygen vacancies that maintain the electron neutrality of the structure when $\mathrm{Co}^{2+}$ replaced $\mathrm{Fe}^{3+}[40]$. Those oxygen vacancies, beside the substantial disruption of the nearest-neighbor magnetic surrounding of $\mathrm{Fe}^{3+}$ cations, could explain the steep reduction of coercivity, as compared to the undoped sample. On sintering the same sample to $1050{ }^{\circ} \mathrm{C}$, the oxygen vacancies are compensated by the oxidation of $\mathrm{Co}^{+2}$ to $\mathrm{Co}^{3+}$ or $\mathrm{Fe}^{3+}$ to $\mathrm{Fe}^{4+}$ with a resulting reduction of the unit-cell volume, a subsequent enhancement of magnetic exchange interaction, and thus an increase in $M_{\mathrm{S}}$. Moreover, the crystallite size has significantly increased (Table 4) producing a partial recovery of coercivity (an increase from 315 to $761 \mathrm{Oe})$.

With higher degrees of $\mathrm{Co}^{2+}$ substitution $(x \geq 0.2)$, the magnetization was significantly diminished; the magnetic behavior of the samples deviated strongly from being ferromagnetic and also saturation magnetization was absent for any of them. Samples sintered at $700{ }^{\circ} \mathrm{C}$ exhibited small differences in magnetization, while all showed almost identical behavior for sintering temperature of $1050{ }^{\circ} \mathrm{C}$. Worth to mention is that, the crystallite size hardly increased with increasing sintering temperature for these samples, and so, no significant changes in $H_{\mathrm{C}}$ was observed. In addition, continuing nonstoichiometric substitution of $\mathrm{Fe}^{3+}$ by $\mathrm{Co}^{2+}$ drastically eliminated the magnetic super interaction between the magnetic moments of $\mathrm{Fe}^{3+}$ cations. In an attempt to provide electron neutrality, the oxidation of $\mathrm{Co}^{2+}$ and/or $\mathrm{Fe}^{3+}$ to nonmagnetic higher valence states is highly probable. This induced both an increase in the distance between nearestneighbor $\mathrm{Fe}^{3+}$ ions and also a reduction of the unit-cell volume; both affect the super-exchange interaction oppositely [41, 42]. With increasing sintering temperature, the concentration of nonmagnetic (low spin state) $\mathrm{Co}^{3+}$ [43] and $\mathrm{Fe}^{4+}$ [44] increases and the cell-volume effect is minimized. Considering both factors, the $M_{20}$ value increases with $x(x \geq 0.2)$ for samples sintered at $700{ }^{\circ} \mathrm{C}$ (Table 3 ), when the effect of unit-cell volume dominates. For the same samples sintered at $1050{ }^{\circ} \mathrm{C}$, the role of high-valence cations dominates that of the cell volume when $M_{20}$ is almost constant with $x$ (Table 4).

It is indeed beneficial that the controlled Co substitution enables the tailoring of the magnetic behavior of $\mathrm{BaFe}_{2} \mathrm{O}_{4}$; it transformed it from hard to soft magnetic material with $\mathrm{Co}^{2+}$ substitution ratio does not exceed $10 \%$. This is a quite desirable characteristic for recording media with low noise level at high recording density [45].

\section{Electrical properties}

\section{Ac conductivity}

Fig. 6 shows the frequency-dependent ac conductivity plot. From this figure, the conductivity shows an increase trend with an increase in frequency for all samples. The conductivity in ferrites may be explained by Verwey's hopping mechanism [46]. According to this mechanism, the electrical conductivity in ferrites is mainly due to hopping of electrons between ions of the same element present in more than one oxidation state. The hopping probability depends upon the separation between ions involved and the potential barrier that must be overcome, which is known as the activation energy for hopping [47]. In addition, the ac conductivity has been related to the hooping of electrons

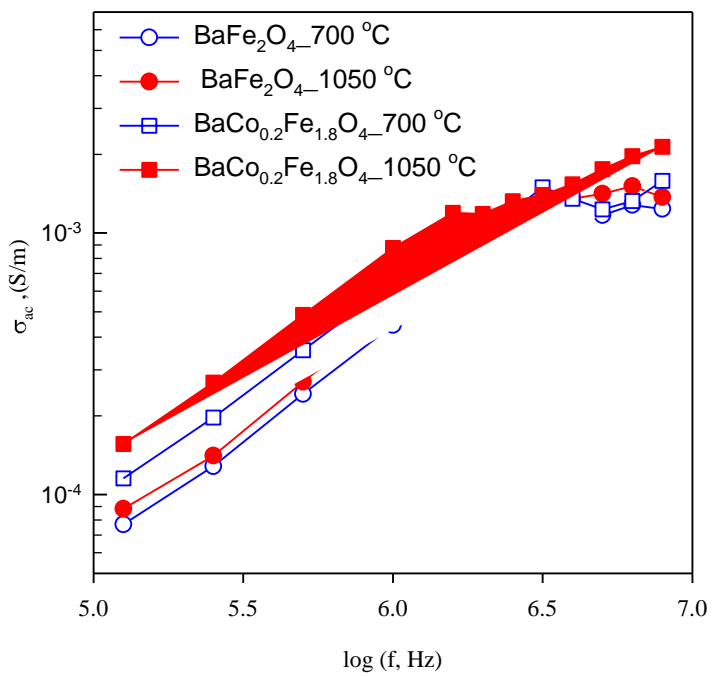


between $\mathrm{Fe}^{3+}$ and $\mathrm{Fe}^{2+}$ and the hopping rate increase with the increase in applied field [48]. As compared to grains, grain boundary is dominant at low frequency which resulting in slow hopping between $\mathrm{Fe}^{2+}$ and $\mathrm{Fe}^{3+}$ ions. While at high frequency, grains influence more that encourage the hope mechanism [49].

An increase in the sintering temperature increases the grain size [50, 51]. Larger size implies the reduction of the concentration of less conductance grain bounders as compared to that of more conductance grains, which enable easier flow for hopping electrons increased and therefore, a lower barrier height. Which could interprets the increase in Ac conductivity with increasing sintering temperature.

\section{Dielectric properties}

The variation of dielectric constant $\left(\boldsymbol{\varepsilon}^{\prime}\right)$ with frequency for pure barium ferrite $\left(\mathrm{BaFe}_{2} \mathrm{O}_{4}\right)$ and cobalt doped barium ferrite $\mathrm{BaCo}_{0.2} \mathrm{Fe}_{1.8} \mathrm{O}_{4}$ sintered at $700{ }^{\circ} \mathrm{C}$ and $1050{ }^{\circ} \mathrm{C}$ has been depicted in Fig. 7.

In all samples the dielectric constant decreases continuously with increasing frequency and becomes almost constant in high frequency region. The decrease in dielectric constant with increasing frequency of applied field is observed by other researchers in a number of ferrite [52]. According to Maxwell-Wagner and Koops theory [53, 54], ferrites consist of highly conducting grains separated by grain boundaries with poor conductance. For ultrafine nanoparticles, grain-boundaries-to-grains volume ratio is quite larger in comparison with their bulk counterparts. The effect of grain boundaries dominates at low frequencies. This observation is in agreement with other researchers [55-57]. At low frequency the space charge polarization is supposed to be responsible for high dielectric constant value. According to Koops model, the charge carriers cause an increase in both space charge and rotational polarizations at the grain boundaries for low-frequency regime. Particles in nano regime have larger surface grains area, which results in larger space-charge polarization and a subsequent increase in $\dot{\varepsilon}$. Furthermore, loosely bound electrons in oxygen anions constitute an additional source for polarization in dielectric materials through aligning themselves along the even small applied electric field [58]. That dielectric polarization with weak electric field is the reason for the recorded high $\varepsilon$ at low frequency. The dielectric polarization in ferrites matches with the mechanism of electrical conduction; it is equivalent to the electronic exchange between ferrous and ferric ions at the octahedral sites $\left(\mathbf{F e}^{2+} \leftrightarrow \mathbf{F e}^{3+}+\mathbf{e}^{-\mathbf{1}}\right)$. The exchange of electron in ferrite systems has been responsible for dielectric polarization i.e. the displacement of electrons in the direction of the applied electric field. The further reduction of $\varepsilon$ with $f$ is attributed to the fact that beyond a certain frequency of external field, the electronic exchange between the ferrous and ferric ions cannot follow the applied electric field [53, 59]. With increasing the sintering temperature, the dielectric constant of a specified sample also increases. This could be attributed to the introduction of sufficient thermal energy for liberating localized dipoles that are capable of aligning themselves with the applied field direction [60]. Worth to noting is that, upon doping $\mathrm{Co}^{2+}$ (for $\mathrm{BaCo}_{0.2} \mathrm{Fe}_{1.8} \mathrm{O}_{4}$ ) the dialectic constant increased which could be attributed to the increased in hopping sites betweenFe ${ }^{3+}$ and $\mathrm{Fe}^{4+}$ and/or $\mathrm{Co}^{2+}$ and $\mathrm{Co}^{3+}$ besides the ferrous and ferric hopping.

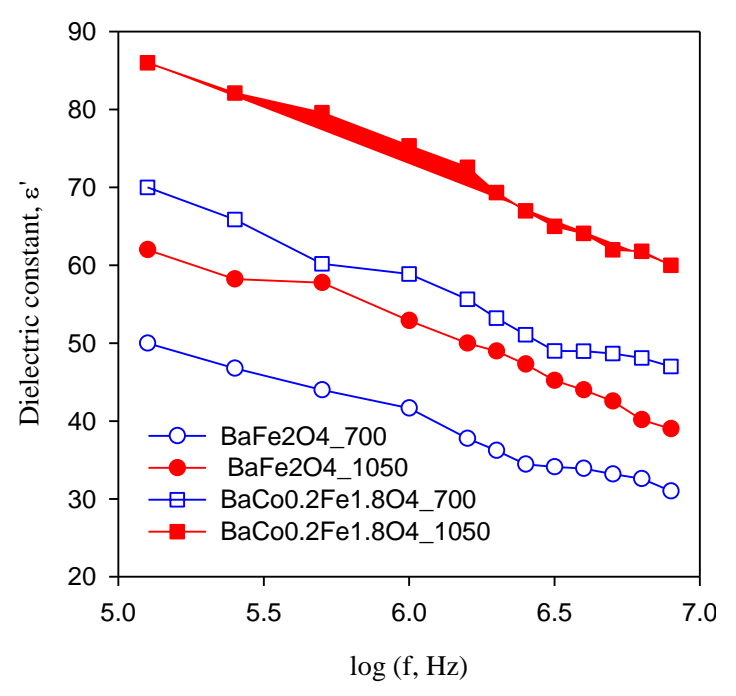

Figure 7. Variation of dielectric constant for $\mathrm{BaFe}_{2} \mathrm{O}_{4}$ and $\mathrm{BaCo}_{0.2} \mathrm{Fe}_{1.8} \mathrm{O}_{4}$ vs. Log (f)

Fig. 8 depicted the variation of dielectric loss $\left(\varepsilon^{\prime \prime}\right)$ as a

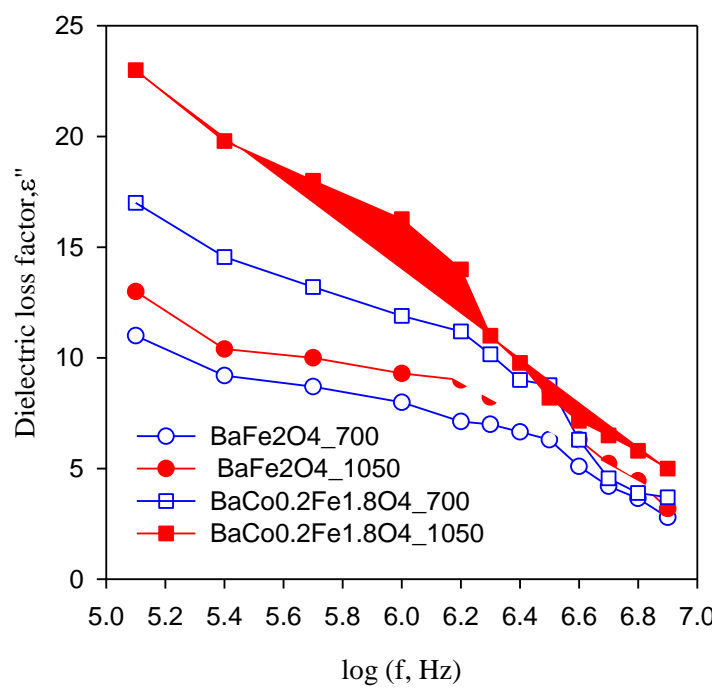

Figure 8. Variation of dielectric loss factor for $\mathrm{BaFe}_{2} \mathrm{O}_{4}$ and $\mathrm{BaCo}_{0.2} \mathrm{Fe}_{1.8} \mathrm{O}_{4}$ vs. $\log$ (f)

function of frequency for pure $\mathrm{BaFe}_{2} \mathrm{O}_{4}$ and $\mathrm{BaCo}_{0.2} \mathrm{Fe}_{1.8} \mathrm{O}_{4}$ sintered at 700 and $1050{ }^{\circ} \mathrm{C}$. At low frequencies, the dipoles interactions are high and decreases with increasing frequency; thereby a remarkable reduction in dielectric loss is observed [61]. Upon introducing Co cations, for $\mathrm{BaCo}_{0.2} \mathrm{Fe}_{1.8} \mathrm{O}_{4}$, both dielectric constant and dielectric loss increase, which could be attributed to oxygen vacancies, grain boundary defects, valence variations and possibly interfacial polarization [62].

\section{CONCLUSION}

A series of Co-doped barium monoferrite compounds $\mathrm{BaCo}_{x} \mathrm{Fe}_{2-x} \mathrm{O}_{4}(0.0 \leq x \leq 0.4)$ have been synthesized by solgel auto combustion method with the subsequent heat treatment at 700 and $1050{ }^{\circ} \mathrm{C}$. XRD confirmed the formation of pure orthorhombic phase for $x=0.0-0.2$, while few traces of $\mathrm{BaFe}_{3} \mathrm{O}_{4}$ and $\mathrm{Ba}_{2} \mathrm{FeO}_{4}$ appeared with increasing either $x$ or sintering temperature. The average crystallite size and unit cell volume were calculated for each sample. The 
unit cell volume are found to decrease with increasing Co content $(x \geq 0.2)$ for both sintering temperature owing to the formation of high valence cations, $\mathrm{Fe}^{4+}$ and/or $\mathrm{Co}^{3+}$. FTIR data has confirmed the phase structure and the presence of higher valence state of $\mathrm{Fe}^{3+}$. The TEM images confirmed XRD calculations. The magnetic behavior of the samples was thoroughly correlated with their structural and compositional properties of the samples. A high degree of flexibility in tailoring $M_{\mathrm{s}}$ and $H_{\mathrm{C}}$ values is suggested in view of the presented discussion. Moreover, the substitution of non-stoichiometric $\mathrm{Co}^{2+}$ ions in mono-barium ferrite results in increasing ac conductivity, dielectric constant and dielectric loss.

\section{REFERENCES}

[1] P. V. Baptista, "Cancer nanotechnology-prospects for cancer diagnostics and therapy," Current Cancer Therapy Reviews, vol. 5, pp. 80-88, 2009.

[2] C. J. Murphy, T. K. Sau, A. M. Gole, C. J. Orendorff, J. Gao, L. Gou, S. E. Hunyadi, and T. Li, "Anisotropic metal nanoparticles: synthesis, assembly, and optical applications," ed: ACS Publications, 2005.

[3] S. Harker, G. Stewart, W. Hutchison, A. Amiet, and D. Tucker, "Microwave absorption and $57 \mathrm{Fe}$ Mössbauer properties of Ni-Ti doped barium hexaferrite," Hyperfine Interactions, vol. 230, pp. 205211, 2015.

[4] I. A. Auwal, A. Baykal, H. Güngüneş, and S. E. Shirsath, "Structural investigation and hyperfine interactions of $\mathrm{BaBi}_{\mathrm{x}} \mathrm{La}_{\mathrm{x}} \mathrm{Fe}_{12-2 \mathrm{x}} \mathrm{O}_{19}(0.0 \leq \mathrm{x}$ $\leq 0.5$ ) hexaferrites," Ceramics International, vol. 42, pp. 3380-3387, 2016/02/01/ 2016.

[5] L. Gonsalves and V. Verenkar, "Synthesis and characterization of nanosize nickel-doped cobalt ferrite obtained by precursor combustion method," Journal of thermal analysis and calorimetry, vol. 108, pp. 877-880, 2012.

[6] S. Majetich, J. Scott, E. Kirkpatrick, K. Chowdary, K. Gallagher, and M. McHenry, "Magnetic nanoparticles and magnetocrystalline anisotropy," Nanostructured Materials, vol. 9, pp. 291-300, 1997.

[7] A. K. Menon and B. Gupta, "Nanotechnology: a data storage perspective," Nanostructured Materials, vol. 11, pp. 965-986, 1999.

[8] M. Rajendran, R. Pullar, A. Bhattacharya, D. Das, S. Chintalapudi, and C. Majumdar, "Magnetic properties of nanocrystalline $\mathrm{CoFe}_{2} \mathrm{O}_{4}$ powders prepared at room temperature: variation with crystallite size," Journal of Magnetism and Magnetic Materials, vol. 232, pp. 71-83, 2001.

[9] A. Mulyawan, W. A. Adi, S. Mustofa, and A. Fisli, "The Phase Transformation and Crystal Structure Studies of Strontium Substituted Barium Monoferrite," in IOP Conference Series: Earth and Environmental Science, 2017, p. 012070.

[10] R. Candeia, M. Souza, M. Bernardi, S. Maestrelli, I. Santos, A. Souza, and E. Longo, "Monoferrite $\mathrm{BaFe} 2 \mathrm{O} 4$ applied as ceramic pigment," Ceramics International, vol. 33, pp. 521-525, 2007.

[11] M. Sugimoto, "The past, present, and future of ferrites," Journal of the American Ceramic Society, vol. 82, pp. 269-280, 1999.

[12] S. Da Dalt, B. B. Sousa, A. K. Alves, and C. P. Bergmann, "Structural and photocatalytic characterization of $\mathrm{BaFe} 2 \mathrm{O} 4$ obtained at low temperatures," Materials Research, vol. 14, pp. 505-507, 2011.

[13] S. Mandizadeh, M. Salavati-Niasari, and M. Sadri, "Hydrothermal synthesis, characterization and magnetic properties of $\mathrm{BaFe}_{2} \mathrm{O}_{4}$ nanostructure as a photocatalytic oxidative desulfurization of dibenzothiophene," Separation and Purification Technology, vol. 175, pp. 399-405, 2017.
[14] R. Candeia, M. Souza, M. Bernardi, S. Maestrelli, I. Santos, A. Souza, and E. Longo, "Monoferrite $\mathrm{BaFe}_{2} \mathrm{O}_{4}$ applied as ceramic pigment," Ceramics International, vol. 33, pp. 521-525, 2007.

[15] I. C. Nlebedim, N. Ranvah, Y. Melikhov, P. Williams, J. Snyder, A. Moses, and D. Jiles, "Effect of temperature variation on the magnetostrictive properties of $\mathrm{CoAl}_{x} \mathrm{Fe}_{2-} \mathrm{O}_{4}$," Journal of Applied Physics, vol. 107, p. 09A936, 2010.

[16] S. Singhal and K. Chandra, "Cation distribution and magnetic properties in chromium-substituted nickel ferrites prepared using aerosol route," Journal of solid state chemistry, vol. 180, pp. 296-300, 2007/01/01/ 2007

[17] A. M. Wahba, M. B. Mohamed, and N. Imam, "Correlating structural, magnetic, and luminescence properties with the cation distribution of $\mathrm{Co}_{0.5} \mathrm{Zn} 0 .{ }_{5+x} \mathrm{Fe}_{2-x} \mathrm{O}_{4}$ nanoferrite," Journal of Magnetism and Magnetic Materials, vol. 408, pp. 51-59, 2016.

[18] A. M. Wahba and M. B. Mohamed, "Structural and magnetic characterization and cation distribution of nanocrystalline $\mathrm{Co}_{x} \mathrm{Fe}_{3-x} \mathrm{O}_{4}$ ferrites," Journal of Magnetism and Magnetic Materials, vol. 378, pp. 246-252, 2015.

[19] J. Dho, E. Lee, J. Park, and N. Hur, "Effects of the grain boundary on the coercivity of barium ferrite $\mathrm{BaFe}_{12} \mathrm{O}_{19}$," Journal of Magnetism and Magnetic Materials, vol. 285, pp. 164-168, 2005.

[20] A. Ataie, M. Piramoon, I. Harris, and C. Ponton, "Effect of hydrothermal synthesis environment on the particle morphology, chemistry and magnetic properties of barium hexaferrite," Journal of Materials Science, vol. 30, pp. 5600-5606, 1995.

[21] J. Wang, "Prepare highly crystalline $\mathrm{NiFe}_{2} \mathrm{O}_{4}$ nanoparticles with improved magnetic properties," Materials Science and Engineering: B, vol. 127, pp. 81-84, 2006.

[22] M. George, A. M. John, S. S. Nair, P. Joy, and M. Anantharaman, "Finite size effects on the structural and magnetic properties of solgel synthesized $\mathrm{NiFe}_{2} \mathrm{O}_{4}$ powders," Journal of Magnetism and Magnetic Materials, vol. 302, pp. 190-195, 2006.

[23] K. Khaja Mohaideen and P. A. Joy, "Influence of initial particle size on the magnetostriction of sintered cobalt ferrite derived from nanocrystalline powders," Journal of Magnetism and Magnetic Materials, vol. 346, pp. 96-102, 2013/11/01/ 2013.

[24] A. R. West, Solid state chemistry and its applications: John Wiley \& Sons, 2014.

[25] S. Castro, M. Gayoso, and C. Rodríguez, "A study of the combustion method to prepare fine ferrite particles," Journal of solid state chemistry, vol. 134, pp. 227-231, 1997.

[26] D. P. Padiyan, A. Marikani, and K. Murali, "Influence of thickness and substrate temperature on electrical and photoelectrical properties of vacuum-deposited CdSe thin films," Materials Chemistry and Physics, vol. 78, pp. 51-58, 2003.

[27] A. K. Zak, W. A. Majid, M. E. Abrishami, and R. Yousefi, "X-ray analysis of $\mathrm{ZnO}$ nanoparticles by Williamson-Hall and size-strain plot methods," Solid State Sciences, vol. 13, pp. 251-256, 2011.

[28] B. Cullity, "Elements of X-ray diffraction: a practical approach," ed: Addison-Wesley Publishing Company Inc., California, 1956.

[29] N. A. Spaldin, Magnetic materials: fundamentals and applications: Cambridge University Press, 2010.

[30] R. Dilip and R. Jayaprakash, "Synthesis and characterization of $\mathrm{BaFe}_{2} \mathrm{O}_{4}$ nano-ferrites for gas sensor applications," Energy, Ecology and Environment, vol. 3, pp. 237-241, 2018.

[31] H. Saravani, M. R. Esmaeilzaei, and M. T. Ghahfarokhi, "Synthesis and Characterization of Ferromagnetic $\mathrm{BaFe}_{2} \mathrm{O}_{4}$ Nanocrystals Using Novel Ionic Precursor Complex $\left[\mathrm{Fe}(\mathrm{opd})_{3}\right]_{2}\left[\mathrm{Ba}(\mathrm{CN})_{8}\right]$," Journal of 
Inorganic and Organometallic Polymers and Materials, vol. 26, pp. 353-358, 2016.

[32] S. Wang, X. Zu, G. Sun, D. Li, C. He, X. Xiang, W. Liu, S. Han, and $\mathrm{S}$. Li, "Highly dispersed spinel $(\mathrm{Mg}, \mathrm{Ca}, \mathrm{Ba})$-ferrite nanoparticles: Tuning the particle size and magnetic properties through a modified polyacrylamide gel route," Ceramics International, vol. 42, pp. 19133-19140, 2016.

[33] Y. Yang, Y. Jiang, Y. Wang, Y. Sun, L. Liu, and J. Zhang, "Influences of sintering atmosphere on the formation and photocatalytic property of $\mathrm{BaFe} 2 \mathrm{O} 4, "$ Materials Chemistry and Physics, vol. 105, pp. 154-156, 2007.

[34] T. Xie, L. Xu, and C. Liu, "Synthesis and properties of composite magnetic material SrCoxFe12-xO19 ( $x=0-0.3)$," Powder Technology, vol. 232, pp. 87-92, 2012/12/01/ 2012.

[35] B. P. Barbero, J. A. Gamboa, and L. E. Cadús, "Synthesis and characterisation of $\mathrm{La}_{1-x} \mathrm{Ca}_{x} \mathrm{FeO}_{3}$ perovskite-type oxide catalysts for total oxidation of volatile organic compounds," Applied Catalysis B: Environmental, vol. 65, pp. 21-30, 2006/05/15/ 2006.

[36] A. Gholizadeh, "The effects of A/B-site substitution on structural, redox and catalytic properties of lanthanum ferrite nanoparticles," Journal of Materials Research and Technology, 2018.

[37] M. B. Mohamed, A. M. Wahba, and Z. K. Heiba, "Effect of Zn substitution on structural, magnetic, and electric properties of $\mathrm{Ni}_{-x}$ $\mathrm{Zn}_{x} \mathrm{Fe}_{1.78} \mathrm{Al}_{0.2} \mathrm{Gd}_{0.02} \mathrm{O}_{4}$ nanoparticles," Journal of Superconductivity and Novel Magnetism, vol. 28, pp. 3675-3683, 2015.

[38] L. Kumar and M. Kar, "Influence of $\mathrm{Al}^{3+}$ ion concentration on the crystal structure and magnetic anisotropy of nanocrystalline spinel cobalt ferrite," Journal of Magnetism and Magnetic Materials, vol. 323, pp. 2042-2048, 2011.

[39] A. Jaafar, S. Arekat, A. Al-Saie, and M. Bououdina, "Structure and magnetic properties of nanosized $\mathrm{BaFe}_{2} \mathrm{O}_{4}$ material," International Journal of Nanoscience, vol. 9, pp. 575-577, 2010.

[40] G. B. Teh, S. Nagalingam, and D. A. Jefferson, "Preparation and studies of Co (II) and Co (III)-substituted barium ferrite prepared by sol-gel method," Materials Chemistry and Physics, vol. 101, pp. 158162,2007

[41] A. Thakur, R. Singh, and P. Barman, "Structural and magnetic properties of $\mathrm{La}^{3+}$ substituted strontium hexaferrite nanoparticles prepared by citrate precursor method," Journal of Magnetism and Magnetic Materials, vol. 326, pp. 35-40, 2013.

[42] H. Wang, Y. Hai, B. Yao, Y. Xu, L. Shan, L. Xu, J. Tang, and Q. Wang, "Tailoring structure and magnetic characteristics of strontium hexaferrite via Al doping engineering," Journal of Magnetism and Magnetic Materials, vol. 422, pp. 204-208, 2017.

[43] N. A. Merino, B. P. Barbero, P. Ruiz, and L. E. Cadús, "Synthesis, characterisation, catalytic activity and structural stability of LaCo1$\mathrm{yFeyO} 3 \pm \lambda$ perovskite catalysts for combustion of ethanol and propane," Journal of catalysis, vol. 240, pp. 245-257, 2006.

[44] J. Yang, X. Zhou, Z. Chu, W. Hikal, Q. Cai, J. Ho, D. Kundaliya, W. Yelon, W. James, and H. Anderson, "Charge disproportionation and ordering in $\mathrm{La}_{1 / 3} \mathrm{Sr}_{2 / 3} \mathrm{FeO}_{3-\delta}$," Journal of Physics: Condensed Matter, vol. 15, p. 5093, 2003.

[45] K. Noma, N. Matsushita, S. Nakagawa, and M. Naoe, "Study on Sand R-block construction with additional spinel blocks in sputterdeposited Ba ferrite films," IEEE Transactions on Magnetics, vol. 33, pp. 3637-3639, 1997.

[46] S. Hussain and A. Maqsood, "Structural and electrical properties of $\mathrm{Pb}$-doped Sr-hexa ferrites," Journal of Alloys and Compounds, vol. 466, pp. 293-298, 2008.
[47] S. M. Ghahfarokhi, F. Ranjbar, and M. Z. Shoushtari, "A study of the properties of $\mathrm{SrFe}_{12-x} \mathrm{Co}_{x} \mathrm{O}_{19}$ nanoparticles," Journal of Magnetism and Magnetic Materials, vol. 349, pp. 80-87, 2014.

[48] M. George, S. S. Nair, K. Malini, P. Joy, and M. Anantharaman, "Finite size effects on the electrical properties of sol-gel synthesized $\mathrm{CoFe}_{2} \mathrm{O}_{4}$ powders: deviation from Maxwell-Wagner theory and evidence of surface polarization effects," Journal of Physics D: Applied Physics, vol. 40, p. 1593, 2007.

[49] D. Paramesh, K. V. Kumar, and P. V. Reddy, "Effect of aluminium substitution on the electrical properties of Ni-Zn nanoferrites," Journal of Magnetism and Magnetic Materials, vol. 444, pp. 371-377, 2017.

[50] R. L. Coble, "Sintering crystalline solids. I. Intermediate and final state diffusion models," Journal of Applied Physics, vol. 32, pp. 787792, 1961

[51] A. Verma, T. Goel, R. Mendiratta, and P. Kishan, "Magnetic properties of nickel-zinc ferrites prepared by the citrate precursor method," Journal of Magnetism and Magnetic Materials, vol. 208, pp. 13-19, 2000.

[52] M. Bhandare, H. Jamadar, A. Pathan, B. Chougule, and A. Shaikh, "Dielectric properties of $\mathrm{Cu}$ substituted $\mathrm{Ni}_{0.5-x} \mathrm{Zn}_{0.3} \mathrm{Mg}_{0.2} \mathrm{Fe}_{2} \mathrm{O}_{4}$ ferrites," Journal of Alloys and Compounds, vol. 509, pp. L113-L118, 2011.

[53] K. W. Wagner, "Zur theorie der unvollkommenen dielektrika," Annalen der Physik, vol. 345, pp. 817-855, 1913.

[54] C. Koops, "On the dispersion of resistivity and dielectric constant of some semiconductors at audiofrequencies," Physical Review, vol. 83, p. 121,1951 .

[55] N. Sivakumar, A. Narayanasamy, B. Jeyadevan, R. J. Joseyphus, and C. Venkateswaran, "Dielectric relaxation behaviour of nanostructured Mn-Zn ferrite," Journal of Physics D: Applied Physics, vol. 41, p. 245001, 2008.

[56] D. Kothari, S. Phanjoubam, and J. Baijal, "Electrical conduction and dielectric behaviour of the oxidic spinel $\mathrm{Li}_{0.5+0.5 x} \mathrm{Cr}_{0.3} \mathrm{Ti}_{x} \mathrm{Fe}_{2.2-1.5 x} \mathrm{O}_{4}$," Journal of Materials Science, vol. 25, pp. 5142-5146, 1990.

[57] R. Manjula, V. Murthy, and J. Sobhanadri, "Electrical conductivity and thermoelectric power measurements of some lithium-titanium ferrites," Journal of Applied Physics, vol. 59, pp. 2929-2932, 1986.

[58] M. J. Iqbal and S. Farooq, "Could binary mixture of $\mathrm{Nd}-\mathrm{Ni}$ ions control the electrical behavior of strontium-barium M-type hexaferrite nanoparticles?," Materials Research Bulletin, vol. 46, pp. 662-667, 2011

[59] K. M. Batoo, S. Kumar, and C. G. Lee, "Influence of Al doping on electrical properties of Ni-Cd nano ferrites," Current Applied Physics, vol. 9, pp. 826-832, 2009.

[60] S. Joshi, M. Kumar, S. Chhoker, G. Srivastava, M. Jewariya, and V. Singh, "Structural, magnetic, dielectric and optical properties of nickel ferrite nanoparticles synthesized by co-precipitation method," Journal of Molecular Structure, vol. 1076, pp. 55-62, 2014.

[61] I. Afandiyeva, I. Dökme, Ş. Altındal, M. Bülbül, and A. Tataroğlu, "Frequency and voltage effects on the dielectric properties and electrical conductivity of Al-TiW-Pd2Si/n-Si structures," Microelectronic Engineering, vol. 85, pp. 247-252, 2008.

[62] Z. Haijun, L. Zhichao, M. Chenliang, Y. Xi, Z. Liangying, and W. Mingzhong, "Preparation and microwave properties of Co-and $\mathrm{Ti}$ doped barium ferrite by citrate sol-gel process," Materials Chemistry and Physics, vol. 80, pp. 129-134, 2003. 